\title{
Bringing Japanese Continuous Improvement Approaches to U.S. Manufacturing: The Roles of Process Orientation and Communications ${ }^{*}$
}

\author{
Thomas Y. Choi \\ Department of Management, College of Business Administration, \\ Bowling Green State University, Bowling Green, OH 43403-0270 \\ Jeffrey K. Liker \\ Department of Industrial and Operations Engineering, University of Michigan, \\ 1205 Beal Avenue, Ann Arbor, MI 48109-2117
}

\begin{abstract}
Continuous improvement (CI) has played a key role in Japan's quality management. U.S. companies have begun to adopt $\mathrm{CI}$ in recent years. This paper studies the implementation of $\mathrm{CI}$ in seven U.S. manufacturing companies. We view values as the core concept of culture that impacts $\mathrm{CI}$ effectiveness. Using both qualitative and quantitative data with a sample of seven companies, we observe empirically a relationship between process-oriented values and CI effectiveness. We also find that communications involving workers is strongly associated with $\mathrm{CI}$ effectiveness. Finally, we find an association between process orientation and communication frequency, and argue that communications act as an intervening variable between process orientation and effectiveness.
\end{abstract}

Subject Areas: Networks, Participation, Quality, Shop Floor Control, Social Issues, Total Quality Management (TQM), and Work Teams.

\section{INTRODUCTION}

Imai [29] and Shingo [61] assert that continuous improvement (CI) as a quality management approach and philosophy has been the single most important factor in Japan's manufacturing success. Imai argues that $\mathrm{CI}$ is "the unifying thread running through the philosophy, the systems, and the problem-solving tools developed in Japan over the last 30 years" [29, p. xxxii]. He points out that CI has been the most important difference between Japanese and Western management styles. Therefore, it is intriguing to learn that while CI may have been developed in Japan, it originated

*This article is based on the first author's doctoral dissertation, completed at the University of Michigan under the direction of the second author. We thank committee members-Daniel Denison, Walton Hancock, William Richards, and Louis Tornatzky - for their comments and suggestions. We also thank this journal's reviewers for their helpful comments on earlier versions of this article. 
in the United States. Schroeder and Robinson [59] argue that CI was brought to Japan from the U.S. after World War II to assist in the rebuilding of Japanese industries. Also, according to Suzaki (as quoted in [44]), CI is the Japanese managers' interpretation of Deming's manufacturing philosophy. Therefore, it seems reasonable for Imai [29] to argue that CI is not a practice peculiar to the Japanese and has implications for all working companies of the world. Schroeder and Robinson agree that although some degree of Japanese success can be attributed to cultural factors, "that is not true as far as continuous improvement programs are concerned" [59, p. 67].

The success of $\mathrm{CI}$ in Japan has not gone unnoticed by U.S. manufacturing managers. It is difficult to find a company that has not implemented, or attempted to implement, some version of CI. However, the result is often a few isolated improvements followed by a lack of enthusiasm, and ultimately, CI is relegated to the shelf of programs that were tried and failed. Choi and Wasti [7] recently observed attempts to implement Japanese quality methods in six U.S. automotive parts suppliers and found that only one had a significant, lasting effect. Why do so many companies fail in their attempts to bring this powerful set of methods and philosophies to the shopfloor?

In this paper we begin with the assumption that $\mathrm{CI}$ in manufacturing is not bounded by national culture and can be effectively implemented in the United States. But this is not to say that culture does not matter. We agree with Brannen [6], who argues that it is not so much national culture but company culture that matters. What she calls "a culture of work" evolves within an organization that may facilitate or inhibit the implementation of what is now thought to be "Japanese quality methods." However, "culture of work" and "culture" as general categories are overly abstract and amorphous. One can hardly imagine where to start in changing such a ubiquitous phenomenon. Thus, we focus on one particular dimension of culture-the value orientation of key members [25] [28]. Drawing on literature from social science and more applied manufacturing management, we make a distinction between two value systems-a results orientation and a process orientation. We then examine the impact of these value orientations through a study of seven U.S. manufacturing companies that were all attempting to implement CI programs.

Arguably, CI is as much a philosophy as a set of specific quality tools and methods. Thus, it would seem to be particularly important for managers to have an orientation toward process, as opposed to results. (By process orientation we mean focusing on the right way of doing things as opposed to the measurable results of particular actions.) $\mathrm{CI}$ has the following generic characteristics: $\mathrm{CI}$ emphasizes the value of making continuous incremental changes as opposed to making a few major discrete changes [29]. Users focus on making small changes, modifying processes, and eventually creating a large cumulative effect [13] [29]. Although each small change may not have a measurable impact, the cumulative effect can be quite profound. $\mathrm{CI}$ also must involve people from all levels and functions in the organization. CI compiles "collective intelligence" by involving everyone in the organization [44], and can "unleash employee experience and creativity to improve both products and processes" [59, p. 67]. The goal is to eliminate wasteful practices [51] [64] and achieve lean production [71]. Workers continuously chip away the fatty tissues of organization and create lean production processes [29] [51] [62]. Suzaki asserted 
that $\mathrm{CI}$ is a kind of meditation technique that reveals its profundity only through ceaseless repetition and change (as quoted in $[44$, p. 80]).

Deming described the essence of $\mathrm{CI}$ as the "constancy of purpose" [56], which is achieved through endless repetition of plan-do-check-act cycles [11]. He believed that CI can only be achieved through process-oriented manufacturing that focuses on improving "process" quality [22]. Imai [29] further contrasts process-oriented thinking and results-oriented thinking in manufacturing management and argues, thus, that process thinking is key in implementing CI. However, this latter concept is not universally accepted. Schaffer and Thompson [57] present an argument for a results orientation in executing improvement efforts, asserting that successful improvement programs in organizations need to focus on results and not process.

Therefore, we empirically examine the impact of a process, as opposed to results, orientation on $\mathrm{CI}$ implementation. Although these value orientations are often discussed as though they are mutually exclusive (cf. [57]), we view them as lying on a continuum, and look at the degree of process orientation in a company. We propose that one of the key mechanisms by which a process orientation works to disseminate enthusiasm for $\mathrm{CI}$ is through informal communication networks [52] [68] [70]. Since effective CI requires involvement of workers, who have traditionally been excluded from quality improvement efforts, we particularly focus on CI communication oriented toward shopfloor workers.

We believe that this study will have implications for any company with a rigid system that stagnates in the routines of merely doing what it does best, but wants to evolve into a system of dynamic routines through implementation of CI. Heeding Imai's argument (as quoted in [14]) that Cl's impact is felt more readily in smaller companies where top management is close to the shopfloor, we focus on small- to medium-sized companies. The research methods used combine qualitative and quantitative approaches. After reviewing relevant literature and developing propositions in the next section, we describe the $\mathrm{CI}$ implementation processes at seven manufacturing companies. Next, quantitative results are presented to examine the propositions. As we study each proposition, we bring in qualitative information to enrich the skeletal relationships delineated by the propositions. We conclude with a discussion of the implications of our results.

\section{THEORETICAL BACKGROUND AND PROPOSITIONS}

This section establishes more rigorously the distinction between process and results orientations in the extant literature. We demonstrate that this dichotomy prevails in the social science literature on human values as well as in the production and operations literature on manufacturing strategy. We present a model that links values, $\mathrm{CI}$ communications directed to workers, and $\mathrm{CI}$ effectiveness.

\section{Value Dichotomy}

Values are often viewed in the literature as a dichotomous concept. That is true for both social scientists and contemporary scholars of quality management we review below.

Social science literature. Kluckhohn [34] distinguished values in terms of a means-versus-ends dichotomy. Whereas the ways of acting are valuable as a means to an end, the ways of acting are also valuable in and of themselves. Rokeach [54] 
[55] took this description of values and reframed it as instrumental values and terminal values. He defined instrumental values as a desirable mode of conduct (e.g., honesty), and terminal values as a desirable end-state of existence (e.g., world at peace). Rokeach argued that both types of values may be sought independently of each another.

Etzioni [18] more recently captured this dichotomy in his discussion of a moralistic value perspective and a neoclassical value perspective. According to the moralistic value perspective, a person strives to do what is socially right here and now, whereas in the case of the neoclassical value perspective, a person strives for the maximal gain as a goal. Likewise, an economic, utilitarian perspective has been contrasted with a behavioral perspective by Hirsch, Friedman, and Koza [27]. The economic perspective focuses on formulation and post-hoc outcomes [26], whereas the behavioral perspective focuses on implementation and process. March and Olsen [36] also suggested that the logic of appropriateness entails people's justifying actions based on culturally accepted social norms and rules. According to the logic of consequence, however, people first isolate the ends and analytically derive the means, which justifies analytically how certain actions are necessary in order to gain a desirable end.

Table 1 summarizes these various conceptions of value dichotomy. Process orientation focuses on people's doing things appropriately in a normatively acceptable way here and now, independent of the availability of clearly rationalized connections to the desirable end state of existence. Results orientation, on the other hand, focuses on their rationalization of the steps required to obtain a strategic goal. It presumes a rational connection between the actions and the intended end state.

Manufacturing literature. An underappreciated contribution of Deming's manufacturing philosophy lies in the distinction between process-oriented manufacturing and goal-oriented manufacturing [22]. Users of the former focus on process and view product quality as a consequence of a quality process, but users of the latter focus on the result and view product quality as a strategic goal. For example, Deming differentiated "zero defects" as a process versus a company goal. He explained that both approaches can lead to zero defects. However, whereas zero defects as a company goal could lead to its achievement at the price of inspection and dismal productivity, improvements in the process can lead to zero defects as a natural consequence. Ishikawa [30] extended this distinction to the general discussion of quality. He argued that one commonly thinks of quality as a trait found in the final product, but it is crucial to think of quality in the process en route to the creation of that quality product.

Imai [29] similarly contrasted the varying implications of process-oriented thinking and results-oriented thinking in management. One implication occurs in the way workers are evaluated. In a marketing example, he illustrated that when evaluating sales people, process-oriented managers focused on the process-based aspects of sales (e.g., the amount of time spent calling on new customers), but results-oriented managers tended to consider the total number of final sales-the bottom line. Another example comes from how the performance of $\mathrm{QC}$ circles are evaluated. According to Imai, the process-oriented criteria are "the number of meetings held per month, the participation rate, and the number of problems solved," whereas the results-oriented criteria often mean "the money saved as the result of their activities" [29, p. 19]. 
Table 1: Summary of value dichotomy in social science literature.

\begin{tabular}{|c|c|c|}
\hline Author & Process-Oriented Terms & Results-Oriented Terms \\
\hline Kluckhohn [34] & $\begin{array}{l}\text { Value as a means in and } \\
\text { of itself }\end{array}$ & Value as an ultimate end \\
\hline Rokeach [54] [55] & Instrumental values & Terminal values \\
\hline Etzioni [18] & Moralistic value perspective & Neoclassical value perspective \\
\hline Hirsch, et al. [27] & Behavioral perspective & Economic perspective \\
\hline March and Olsen [36] & Logic of appropriateness & Logic of consequence \\
\hline
\end{tabular}

Juran [33] differentiated between quality improvement, which is process driven, and quality planning, which is goal driven. The actions that are necessary in improving a quality process are differentiated from the strategic plans that are defined to create a quality product. Nakajima [41] compared preventive maintenance, wherein managers focus on preventing undesirable results typically based on a fixed maintenance schedule, to productive maintenance, wherein they focus on involving people in maintenance during the process of work. Dertouzos, Lester, and Solow [13] contrasted two product design philosophies: product design is either seen as comprising incremental steps focused on the process, or seen as a discrete jump focused on the projected results. Robinson [51] contrasted manufacturing-driven management, which focuses on the process of manufacturing, and profit-driven management, which focuses on the results of manufacturing. These ways of looking at this value dichotomy are summarized in Table 2 .

The manufacturing literature is more prescriptive than the social science literature and tends to prescribe a process orientation. For example, Imai [29] attributed the success of Japanese manufacturing to process-oriented thinking. He pointed out that results-oriented management is probably a remnant of the mass-production legacy and that process-oriented management is more suited for the postindustrial, high-tech, high-touch society. He asserted that the fortuitous matching of the process-orientation of $\mathrm{CI}$ and the process-oriented Japanese management has been the underlying cause of the heralded manufacturing success of Japan.

Although there have been many assertions about the importance of processoriented values in CI, we know of no empirical tests. In the next section we develop a model that we examine using data from the seven companies.

\section{THE MODEL}

The theoretical model is summarized in Figure 1. It is a mediating model (see [2]) that assumes both a direct relationship between process orientation and $\mathrm{CI}$ effectiveness, and an indirect relationship mediated by the $\mathrm{CI}$ communication variables. The direct relationship suggests that communication is not the only mechanism by which processoriented values influence $\mathrm{CI}$ effectiveness. For example, process-oriented managers are more apt to dedicate human and financial resources to making the CI program work. We will consider each of the links in this model and formulate formal propositions. 
Table 2: Summary of value dichotomy in manufacturing literature.

\begin{tabular}{lll}
\hline Author & Process-Oriented Terms & Results-Oriented Terms \\
\hline Deming [22] & Process quality & Product quality \\
Ishikawa [30] & Quality as process & Quality as results \\
Imai [29] & Process-oriented thinking & Results-oriented thinking \\
Juran [33] & Quality improvement & Quality planning \\
Nakajima [41] & Productive maintenance & Preventive maintenance \\
Dertouzos, et al. [13] & $\begin{array}{l}\text { Incremental product } \\
\text { design }\end{array}$ & Innovative product design \\
& $\begin{array}{l}\text { Manufacturing driven } \\
\text { management }\end{array}$ & Profit driven management \\
\hline
\end{tabular}

\section{Implications of Value Orientations for CI Effectiveness}

There is considerable agreement in the contemporary quality management literature that process orientation is more integral than results orientation in achieving CI. According to Gabor [22], Deming's interest was in the process of work and the people who try to achieve constancy of purpose through plan-do-check-act cycles. Deming argued that process-oriented thinking leads more readily to systematic change efforts through $\mathrm{CI}$; meanwhile, results-oriented thinking leads to individualistic change efforts and finance-driven management. The Japan Management Association [31] similarly noted that the only real source of profit or value added is the manufacturing process. The value added can never be accomplished through financial ingenuity.

Ishikawa [30] similarly pointed out that a quality process is a prerequisite to quality results. Nemoto [42] defined quality as reduction of defectives within the process through $\mathrm{CI}$, meaning that quality process comes before quality results. Schonberger [58] likewise argued that quality as a process can lead to productivity, but productivity as a result will not lead to quality. Townsend [69] further argued that the phrase, "quality has value," connotes a process that has no ending but becomes part of the company culture.

In discussing strategy for machine maintenance, Nakajima [41] and Suzaki [64] proposed productive maintenance as the ultimate level in machine maintenance over and beyond preventive maintenance. They argue that conducting maintenance on a continual basis during the process of production is superior to maintaining machines based on some predefined schedules. Dertouzos and colleagues [13] suggested that product design as incremental steps focused on process is superior to product design as discrete jumps focused on projected results. They explain that the former tends to promote cooperation across functions, whereas the latter tends to promote individual specialists working alone in a more segmented way.

Imai [29] stated that the CI concept epitomizes Japan's process-oriented thinking, which has been proven much more effective in quality management than the 
Figure 1: Theoretical model relating value orientations, $\mathrm{CI}$ communications, and the effectiveness of $\mathrm{CI}$.

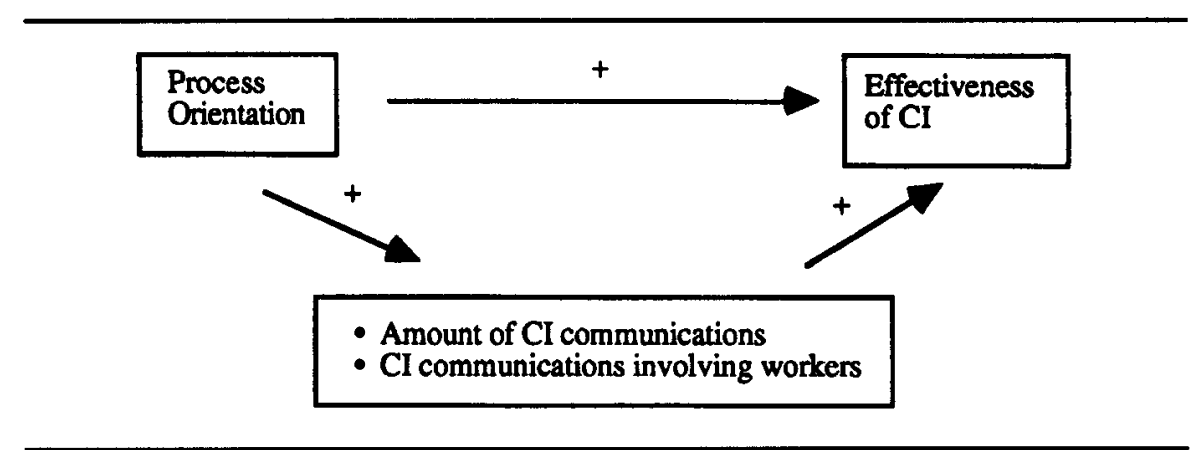

results-oriented thinking characteristic of the West. Process-oriented management, which supports and stimulates the efforts for continuous improvement, is more effective in achieving lean production than results-oriented management, which controls the performance of the workers with a carrot and stick. Etienne-Hamilton [17] argued that CI is best managed as a steady process of sustainable improvements rather than results-driven, discrete changes.

Thus, CI seems to naturally correspond to a process-oriented focus. Resultsoriented managers are apt to be frustrated by many little changes that cannot individually be cost-justified. They will be much more comfortable with "home run" innovations that have big, quantifiable benefits, even though they will cost more (e.g., buying expensive new technology). This leads to the following proposition:

Proposition 1: A process orientation, compared to a results orientation, is positively associated with the effectiveness of $\mathrm{CI}$.

\section{The Intervening Role of General CI Communications}

We have argued that CI requires a new way of thinking: from an emphasis on stability and control, to an emphasis on ongoing change and improvement. We also argued that to be effective, $\mathrm{CI}$ depends on the energy and commitment of people at all levels and across functions. Many new programs of the month come and go, and there is often skepticism toward any new program. How does a shift in work attitude occur?

Scholars in the field of communication have focused on how individuals' attitudes change through social networks [48] [70]. For example, Rogers and Kincaid [53] demonstrated through network analysis how peoples' attitudes changed regarding a social program in rural villages of Korea. Rogers [52] subsequently argued that although information can be diffused through impersonal sources, attitude and behavioral changes are more likely to occur through interpersonal sources. Rice and Aydin [46] found organization members' attitudes toward a new information technology can be influenced through social networks, and Rice, Grant, Schmitz, and Torobin [47] found an influence of social networks in employees' adoption of an electronic mail system. 
To a large extent, the dissemination of $\mathrm{CI}$ in organizations becomes a problem of social influence. It occurs within social networks where people meet, interact, and influence one another. Tichy [66] [67] [68], in particular, asserted the importance of social influence and communication networks in managing organizational change. Because $\mathrm{CI}$ represents an important aspect of organizational change, we expect that a prerequisite for successful change is active communication about $\mathrm{CI}$ through communication networks. Thus:

Proposition 2a: The amount of CI communication is positively related to the effectiveness of $\mathrm{CI}$.

Our model predicts that process-oriented implementers are more likely to communicate about $\mathrm{CI}$ than results-oriented implementers. There are several reasons to expect this: First, we have argued that process-oriented managers are more likely to be committed to $\mathrm{CI}$. And, it follows that they will spend more time investing in what it takes to make it work, including communications. Second, process-oriented leaders are more likely to see communications as integral to implementation, and the right thing to do. Results-oriented managers may both feel there are no tangible returns to communication and become impatient with "a lot of talk." Their focus is apt to be on the tasks involved in achieving concrete results rather than on the process of change needed to support the less tangible shift in philosophy. This leads to the following proposition:

Proposition 2b: Process orientation is positively related to the amount of CI communications.

\section{The Intervening Role of CI Communications Directed to Workers}

In particular, communication to workers is crucial when implementing CI. Deming [11] and Imai [29] pointed out explicitly that the success of CI depends on involving workers in the improvement process. Many other authors (e.g., [23], [33], and [59]) restate this observation.

Because the incremental changes are inherently intertwined in everyday work activities, the workers need to be at the center of CI activities [31]. For companies, the challenge is to improve work routines and not just make cosmetic changes [11]. To successfully accomplish this, workers need to supply ideas and implement them, and managers must support these activities [51]. The following proposition does not distinguish between communications directed to workers and communications coming from workers, although we will examine separate measures of each:

Proposition 3a: CI communication involving workers is positively related to the effectiveness of $\mathrm{CI}$.

The same argument for the relationship between process orientation and general CI communications applies even more strongly for CI communications directed toward workers. Traditionally, workers were not involved in quality control. It was seen as more effective and expedient to have staff functions assigned to quality: 
workers worked and staff functions did the thinking. The philosophy of $\mathrm{CI}$ suggests that workers should do and think. This is a difficult transition for managers used to having external control over workers. It requires some degree of trust that workers are capable of contributing to quality improvement, and that they will not exploit the lack of external control to "get off easy," and perform substandard work. In short, it requires faith in the process. It is difficult to provide the kind of hard evidence that a results-oriented manager would desire to demonstrate conclusively that workers can contribute to quality. It requires a leap of faith that comes more easily to the process-oriented manager. Unless managers buy into the key role of workers, they are not likely to bother to invest the time and resources needed to keep workers informed and involved. Thus, we propose the following:

Proposition 3b: Process orientation is positively related to CI communications involving workers.

\section{METHODS}

Our research utilizes quantitative and qualitative approaches. The quantitative methodology is mainly built on social network analysis, and the qualitative methodology is based on a longitudinal case study approach. The key purpose of the quantitative methodology is to statistically examine the relationships between the independent measures and dependent measures. The key purpose of the qualitative methodology is, in contrast, to enrich these skeletal relationships with contextual information. The social network data were collected cross-sectionally through a questionnaire, whereas the case study data were collected longitudinally through interviews over a one-year time period.

The idea of using multiple methods to understand complex organizational processes is certainly not new. Calls for triangulation of methods are rampant in the literature [9] [10] [15] [19] [32]. However, actual data-gathering efforts using multiple methods are relatively rare, with some notable exceptions (e.g., [12] and [38]). In the study described here, we intensively studied a small number of sites and gathered rich descriptions of process over time. We then collected the quantitative data on social networks and outcomes of CI efforts. We subsequently integrated the results from different data sources.

\section{Sample}

The seven manufacturing sites chosen for this study are all located in the Detroit area. They were all members of the same CI training and support group known as the CI Users Group (CIUG) [20]. The sample sites were small- to medium-sized companies, ranging from 25 to 160 employees. They were all suppliers to the automotive industry. They consisted of three stamping plants, two fastener manufacturers, one machine tool builder, and one assembly plant. All seven companies were first exposed to $\mathrm{CI}$ at the same time-when they joined the CIUG. All seven companies were well-established and financially stable, having consistently reported profits during the five years prior to the study. There was only one plant represented from each company, and we focused on the operation of these plants. Therefore, we use the terms, plant and company, interchangeably in this paper. 
The survey respondents were identified as the "key organizational actors" in the implementation of the CI program. All managers were first identified as key actors because of their authority to make decisions that affect $\mathrm{CI}$ activities in the company. Then, a group of staff and workers who participated in CI activities were identified using a snowball sampling technique [3]. We started with the two people who attended the CIUG, and asked each person to suggest additional names of people who participated in CI activities. In all, 169 people responded to the CI survey.

\section{Quantitative Measures}

Predictor variables. The survey was conducted in August 1991. Both the value orientations and the prevalence of communication about $\mathrm{CI}$ were measured by asking each respondent about all of the other respondents in the sample (see Appendix A). The questionnaire was customized for each company with the names of respondents from each company appearing under these questions. The respondent rated his/her frequency of communication about $\mathrm{CI}$ with each person on the list and the value orientation of that person. The overall response rate ranged from 85 to 100 percent.

The questions that probed for the value orientations of each respondent presented three situations related to manufacturing: work ethics, customer satisfaction, and investing. For each situation, the respondents were asked which of two choices best fit the likely behavior of each person listed. For example, for the question posing the following prompt: "When doing a job, this person will ...?" one option represented a process-oriented reaction (e.g., get it done right at all cost), whereas the other represented a results-oriented reaction (e.g., get it done as efficiently as possible in minimum time). The wording of the choices was selected to avoid the appearance of socially acceptable response. The internal consistency of value measures were verified by showing statistically that the within-company variance of value orientation scores is significantly less than the between-company variance ( $F=8.79$; $p<0.001$ ).

The value measure was computed in two steps. First, we accumulated the ratings of each person by all other respondents to get a measure of that person's value orientation. The value orientation of each person was treated as a dichotomyhe or she was coded as either process- or results-oriented, based on the preponderance of evaluations by others. Each person's value orientation was coded by taking the average of observed value orientations, which ranged from 0 to 1 , and using 0.5 as a point cutoff. Second, the percentage of process-oriented members was computed for each company by simply taking the ratio of the number of process-oriented people to the total number of people. This provided a continuous measure of the degree of process versus results orientation of the company. It is this company-level measure that is used in the analysis.

One might ask why we used a dichotomous measure to classify individual value orientations prior to aggregating by company. This was done mainly because the resulting measure of percent process-oriented has intuitive merit-the results are easy to present and the tables are easy to interpret. We could have used a continuous measure with less intuitive merit; for example, averaging the degree of process orientation across key actors and computing correlations between this measure and 
other measures, but this leads to almost identical results. In fact, the correlation between our dichotomized measure of company-level value orientation and the measure on a continuous scale is 0.97 .

The other predictor variables were communication measures. As before, each respondent was asked about the level of $\mathrm{CI}$ communications between themselves and each of the other respondents on the list. The level of communications between two individuals varied from "never" to "rarely" to "occasionally" and to "often," a 0 to 3 scale. Therefore, in the end, an $\mathbf{N x N}$ matrix is generated for each company, where $\mathbf{N}$ is the number of respondents, and each element in this matrix has a value ranging from 0 to 3 . Because each element $(i, j)$ in the matrix signifies the frequency of communication from person $i$ to person $j$, the matrix is asymmetric where the level of communication from $i$ to $j$ is not necessarily reciprocated at the same level.

We used two computer software packages to generate measures from the matrices. FATCAT [49] was used to compute the amount of overall CI communications with all other members, as well as the level of CI communications to and from workers. The advantage of FATCAT is that it can handle the contextual information (e.g., whether someone is a worker or a manager) superimposed on the communication matrix. When operating on the matrix to compute the level of communication, a cutoff value of 2 (occasionally) was used to determine the existence of a relationship. The cutoff value of 2 accepts communications that occur either "often" or "occasionally," and rejects communications that occur either "never" or "rarely."

UCINET IV [4] was used to compute a communication structural index called degree centrality (see [21]). Degree centrality is a measure of level of communications at the individual level [21] [60]. To say a person has a high degree centrality means that the degree of communication lines connected to that person is high. It means that the person represents a central node in the communications network. Degree centrality scores of all workers in each company were averaged to get a company level indicator of the overall level of $\mathrm{CI}$ communication with workers in each company. To compute the level of $\mathrm{CI}$ communications directed to workers, the asymmetric matrices were used, because they offer directional information (e.g., communications going in and coming out are separated). However, to compute the overall level of $\mathrm{CI}$ communications to and from workers, the asymmetric matrices were transformed to the symmetric matrices. This was done by using an option in UCINET that can compute the mean of the $(i, j)$ and $(j, i)$ values. The mean was used because there was no reason to assume that either $(i, j)$ or $(j, i)$ was more accurate or influential.

Outcome variables. There were three types of outcome variables measuring CI effectiveness: respondents' perceptions, outside observers' ratings, and performance records. The respondents' perception of $\mathrm{CI}$ effectiveness came from a survey question that asked each to rate the general impact of $\mathrm{Cl}$ on his or her company on a scale of 1 to 4 (i.e., $1=$ hardly any, $2=$ little, $3=$ fairly much, and $4=$ extensive). The scores were averaged in each company across all respondents.

The outside observer ratings came from three consultants who had been working with the companies through the CIUG and visited these companies a number of times between the formal meetings. They were asked to rate the effectiveness of CI in each company based on their personal knowledge of the companies and on a listing of major $\mathrm{CI}$ activities for each company generated by the researchers through 
interviews in the company (summarized in Table 3). The consultants were asked to rate, independently, the companies on four aspects of $\mathrm{CI}$ activities: level of $\mathrm{CI}$ accomplishments, level of CI philosophy taking hold, level of waste elimination, and overall impact of CI. Each aspect was rated on a scale from 1 to 5 ; namely, 1 was the least favorable and 5 was the most favorable. The ratings across the three consultants had approximately 80 percent agreement. Their ratings were subsequently averaged to give a single measure for each company.

Managers at each company were asked to submit their company's performance records for 1990 and 1991, before and after the companies began to pursue CI. Managers were asked to supply three types of performance measures: productivity, quality, and inventory. The quality measures were based on three components: internal rejects (rejected through their inspectors), external rejects (rejected by the customer), and scrap (rejected material not reworked). The inventory measure was also based on three components: raw inventory, work-in-process (WIP) inventory, and finished inventory. The unit of inventory varied from company to company: Some used weight of parts, whereas others used number of parts.

Only four of the seven companies supplied the records. No company supplied complete records on all seven dimensions. Only the ratios of improvement between 1990 and 1991 were permitted to be published. We present all the data we have obtained as supplements to the other outcome measures.

Analysis methods. The unit of analysis is at the plant level, which provides a sample size of only seven. We use bivariate correlation coefficients for measures of association. The qualitative interpretation of differing levels of association is adopted from Guilford [24].

With such a small sample, we could not partition out the direct and indirect effects. That is, we could not use partial correlations to separate out the direct effects of values on effectiveness from the indirect effects operating through communications. So, for example, we test whether there is a relationship between process orientation and $\mathrm{CI}$ communications (between process orientation and $\mathrm{CI}$ communications) and between $\mathrm{CI}$ communications and $\mathrm{CI}$ effectiveness, but we do not know what portion of the effect of value orientations on effectiveness operates indirectly through communications.

\section{Qualitative Data}

Comparative case approach. The comparative case approach is used here to complement the survey data. Whereas the survey takes place at one point in time, the case studies were based on longitudinal observation over a period of time before and after the survey to address the process dynamics within organizations. Yin [72, p. 23] argued that "surveys can try to deal with phenomenon and context, but their ability to investigate the context is extremely limited."

The case studies mainly relied on interviews and documents. The CIUG participants were first interviewed. As more people who were involved in CI internally became identified based on the snowball sampling, they also were interviewed. By the end of 1991, everyone who was identified as having been involved in CI had been interviewed at least once. Each visit took four to eight hours, and each interview lasted from 30 to 60 minutes. 
Table 3: Summary of CI activities by plant.

\begin{tabular}{|c|c|c|}
\hline Company & $\begin{array}{l}\text { Number of CIUG } \\
\text { Participants }\end{array}$ & Key CI Activities \\
\hline Progressive & 3 & $\begin{array}{l}\text { Shuts down the whole plant to "clean up and throw } \\
\text { stuff out." } \\
\text { Housekeeping and workplace organization } \\
\text { committee organized and given an autonomous } \\
\text { budget. } \\
\text { Each department is asked to submit CI changes each } \\
\text { month. } \\
\text { A bulletin board is set up to display change lists and } \\
\text { to show quality and production data. } \\
\text { The housekeeping and workplace organization } \\
\text { committee reviews each department every month } \\
\text { and gives out awards. } \\
\text { Preventive maintenance training gets underway. }\end{array}$ \\
\hline Sunshine & 2 & $\begin{array}{l}\text { Problem board instituted. } \\
\text { Involves workers in the new employee hiring. } \\
\text { Suggestion program for quality improvement. } \\
\text { Scrap reduction group organized. } \\
\text { Five CI committees organized and given specific tasks. } \\
\text { Plant layout gets a new configuration based on } \\
\text { TQM principles. }\end{array}$ \\
\hline Heat & 3 & $\begin{array}{l}\text { Internal CI group organized. } \\
\text { Suggestion program started. } \\
\text { Suggestion reward system instituted. } \\
\text { Sets up a display board to celebrate accomplishments. }\end{array}$ \\
\hline Topheavy & 3 & $\begin{array}{l}\text { Sporadic meetings. } \\
\text { Attempts to relocate die racks. } \\
\text { Extensive worker training takes place but its } \\
\text { impact remains uncertain. }\end{array}$ \\
\hline Mom and Pop & 3 & $\begin{array}{l}\text { Designs a die cart. } \\
\text { Sets up a communication board. }\end{array}$ \\
\hline Small & 2 & $\begin{array}{l}\text { Paints one work room. } \\
\text { Dies are color-coded. } \\
\text { Reorganizes work racks and cleans floors of oil stains. }\end{array}$ \\
\hline Nuts and Bolts & 3 & $\begin{array}{l}\text { Several tool boxes get organized. } \\
\text { Setup checklist instituted. } \\
\text { Tool staging cabinet constructed. } \\
\text { Peg boards for tool organization installed. } \\
\text { Generic area tools get labeled. } \\
\text { The organizational infrastructure is overhauled. }\end{array}$ \\
\hline
\end{tabular}


The actual site visits began in March of 1991. At first, we focused the interviews on the events that had occurred since the company joined the CIUG. In this phase of the data collection, the data mainly came from the respondents' recollection of the events since October 1990. Documents (e.g., minutes of the meetings, internal memos) were collected to cross-check as well as to complement the retrospective data. At this time, our mode of data collection was that of "catching up," and the companies were visited several times a week until it was felt that the events were brought up to date. We believed the retrospective data collection was saturated when the same information began to repeat itself among different interviewees [16]. After this point, we visited each of the seven sites approximately once a month until December 1991. We visited sites approximately once every two months in 1992 until April.

At the end of each visit we transcribed notes into a case history. When we visited the same company on two consecutive days, we occasionally transcribed the notes after the second visit. In all cases, we handled the transcribing within 24 hours of the last visit. This resulted in about ten such case records for each site.

Case background. Although all companies were subjected to the same training through the CIUG, the process unfolded at each company quite differently. Each company followed its own unique path to the implementation of CI. Next, we describe the seven companies in order from the most process-oriented company to the least process-oriented company, which corresponds quite strongly to the degree of $\mathrm{CI}$ effectiveness, as will be shown later. The names of the seven companies have been changed to ensure anonymity. Pseudonyms are assigned to characterize each company.

Progressive was regarded by the other six companies as the "model company," and its CI approach was most progressive. Sunshine had a pleasant and cordial work atmosphere compared to the other six companies, and its main product was the sunroof. Heat had one leader who spearheaded its $\mathrm{CI}$ program and subsequently got ample "heat" from the management. It also manufactures induction heating equipment. Topheavy included only managerial personnel in its CI committees. Mom and Pop was described as such by the workers because most of the top managerial positions were filled by the family members who owned the company. Small was a minority-owned company that was the smallest of all seven companies. Nuts and Bolts was the most results-oriented company, and it manufactures fasteners.

Brief case descriptions of the major $\mathrm{Cl}$ activities and outcomes for each of the seven companies are included in Appendix B. Table 3 provides a summary of the key $\mathrm{CI}$ activities in the seven companies.

\section{RESULTS}

We organize the results around the propositions. For each proposition we first present the quantitative results, followed by supporting qualitative observations.

\section{Process Orientation and CI Effectiveness (P1)}

Quantitative results. The process orientations of key implementers in the seven companies are summarized in Table 4. The companies with higher percentages of processoriented respondents are listed first. As a more general classification, two companies were identified as process-oriented, two as mixed, and three as results-oriented. 
There seem to be natural breaks between them in terms of the percentage of process orientation in each company. For example, the two process-oriented companies had a majority of respondents with process orientations; the two mixed companies had process-oriented implementers in the 30 to 40 percent range; and the results-oriented companies had only about 10 percent process-oriented implementers. The last column of Table 4 describes examples of each company's value orientation.

The level of process orientation correlates with the perceived impact of CI and the rated effectiveness of $\mathrm{CI}$ in Table 5. The correlations are high and they support Proposition 1 . The more process-oriented a company is, the more likely it is effective in $\mathrm{Cl}$ activities. Moreover, this result is reinforced when comparing the value orientations with more objective measures of company performance as shown in Table 6 .

Only four of the seven companies supplied performance records; the other three companies did not collect these performance data. We report here all the data we were able to collect and were permitted to publish. The results are intended to be suggestive, not conclusive. The dimensions for which no records were kept appear as "na" in Table 6. All scores signify the rate of improvement. Note that all quality and inventory measures are normalized by the annual gross sales in dollars prior to the computation of the improvement ratios. This is done because those scores are dependent on production volume, and the sales amount is considered a good indicator for the production volume.

In line with the qualitative assessments of CI effectiveness we see that Progressive and Sunshine have relatively high improvements on quality measures compared to the relatively low scores of Mom and Pop and Nuts and Bolts. We discuss this in greater depth under the qualitative observations section.

Qualitative observations. Progressive and Mom and Pop make a useful illustrative contrast in value orientations and $\mathrm{CI}$ effectiveness. Both companies started to implement participative management at about the same time, just before they joined the CIUG. One excelled in CI but the other lagged. By the end of the following year, they were at the extreme ends of the Cl effectiveness spectrum. Members of Progressive somehow managed to make their CI program a great success (4.0 and 4.2 on the CI effectiveness measures), whereas members at Mom and Pop were struggling to make a few changes (2.6 and 1.2 on the $\mathrm{CI}$ effectiveness measures).

Note that these two companies were also on the opposite ends of the spectrum of value orientations. Progressive was overwhelmingly process-oriented, while Mom and Pop was overwhelmingly results-oriented. This fundamental difference in their value orientations lines up in a perfectly reversed way with their $\mathrm{CI}$ effectiveness indicators. Moreover, it also lines up in a reversed way with their quality records as shown in Table 6, in particular, with external reject records. Although their internal records were similarly improved (4.35 and 4.17) from 1990 to 1991, their external records, which reflect product rejected by the customer and sent back, showed very different improvement rates. Progressive improved its external rejects by about two times (2.22), but Mom and Pop had reduced external quality (e.g., greater rejects) by about three times $(0.35)$. This suggests that even though Progressive's internal reject improvement rate correctly reflected its improved work process, Mom and Pop regarded many marginal parts as good, only to see them eventually get rejected by customers. One worker at Mom and Pop commented, "We are told to make a lot of parts in a very short time .... I have no confidence in how we are 
Table 4: Value orientations of seven companies.

\begin{tabular}{|c|c|c|c|c|}
\hline Companies & $\begin{array}{c}\text { Total } \\
\text { Number of } \\
\text { Respondents }\end{array}$ & $\begin{array}{l}\text { Percent } \\
\text { Process } \\
\text { Oriented }\end{array}$ & $\begin{array}{l}\text { Qualitative } \\
\text { Level of Value } \\
\text { Orientation }\end{array}$ & Examples \\
\hline Progressive & 29 & 83 & Process & $\begin{array}{l}\text { "We focus on doing the right } \\
\text { things and let the productivity } \\
\text { and quality improvements take } \\
\text { place in due course." }\end{array}$ \\
\hline Sunshine & 17 & 65 & Process & $\begin{array}{l}\text { "When we make an } \\
\text { improvement, we want it to } \\
\text { improve the work process rather } \\
\text { than be a quick fix." }\end{array}$ \\
\hline Heat & 41 & 37 & Mixed & $\begin{array}{l}\text { "Some managers say they get } \\
\text { into making changes, but most } \\
\text { won't even consider making } \\
\text { changes unless they lead to big } \\
\text { time savings." }\end{array}$ \\
\hline Topheavy & 27 & 33 & Mixed & $\begin{array}{l}\text { "Management says that they are } \\
\text { interested in ideas from workers, } \\
\text { but they sure don't act like they are." }\end{array}$ \\
\hline $\begin{array}{l}\text { Mom and } \\
\text { Pop }\end{array}$ & 18 & 14 & Results & $\begin{array}{l}\text { "They (management) are more } \\
\text { interested in meeting today's } \\
\text { production than how we can } \\
\text { improve the process for next month." }\end{array}$ \\
\hline Small & 11 & 10 & Results & $\begin{array}{l}\text { "As long as we can send out } \\
\text { good parts, we will double or } \\
\text { triple the inspection personnel." }\end{array}$ \\
\hline $\begin{array}{l}\text { Nuts and } \\
\text { Bolts }\end{array}$ & 26 & 8 & Results & $\begin{array}{l}\text { "Workers have got to make this } \\
\text { change. It has been proven to } \\
\text { save time." }\end{array}$ \\
\hline
\end{tabular}

doing in product quality." This company was downsizing toward the end of 1991, and its production crew was often shorthanded.

\section{The Intervening Role of General CI Communications (Propositions 2a and 2b)}

Quantitative results. In Table 7, the correlation of the percent CI communication with the perceived $\mathrm{CI}$ impact is high at 0.77 , with up to 59 percent of the variance explained, though lower with rated $\mathrm{CI}$ impact at 0.34 . Both correlations are positive, lending support for Proposition 2a. The association between CI communication and 
Table 5: Process orientations and CI effectiveness.

\begin{tabular}{lccc}
\hline Companies & $\begin{array}{c}\text { Percent } \\
\text { Process-Oriented }\end{array}$ & $\begin{array}{c}\text { Mean Respondent } \\
\text { Perceived CI Impact }\end{array}$ & $\begin{array}{c}\text { Mean Observer Rated } \\
\text { CI Effectiveness }\end{array}$ \\
\hline Progressive & 83 & 4.0 & 4.2 \\
Sunshine & 65 & 2.9 & 3.4 \\
Heat & 37 & 2.1 & 2.0 \\
Topheavy & 33 & 2.8 & 2.3 \\
Mom and Pop & 14 & 2.6 & 1.2 \\
Small & 10 & 2.3 & 1.1 \\
Nuts and Bolts & 8 & 2.8 & 3.0 \\
\hline
\end{tabular}

$r=0.72$ between process orientation and perceived impact of $\mathrm{CI}$.

$r=0.79$ between process orientation and rated effectiveness of $\mathrm{CI}$.

Table 6: Summary of performance improvement, 1990-91. ${ }^{\text {a }}$

\begin{tabular}{|c|c|c|c|c|c|c|c|}
\hline & \multirow[b]{3}{*}{ Productivity } & \multicolumn{3}{|c|}{ Quality Measures } & \multirow{2}{*}{\multicolumn{3}{|c|}{ Inventory Measures }} \\
\hline & & & Internal & External & & & \\
\hline & & Scrap & Rejects & Rejects & Raw & WIP & Finished \\
\hline Progressive & 1.04 & na & 4.35 & 2.22 & 1.22 & 0.79 & 1.62 \\
\hline Sunshine & 1.07 & 2.45 & na & na & & $1.52^{\mathrm{b}}$ & \\
\hline Mom and Pop ${ }^{c}$ & na & 1.58 & 4.17 & 0.35 & 1.04 & 1.56 & 0.57 \\
\hline Nuts and Bolts & 1.10 & 1.10 & na & na & 1.27 & na & na \\
\hline
\end{tabular}

${ }^{a}$ Any number greater than 1.0 indicates improvement, and any number less than 1.0 indicates decline.

${ }^{b}$ This score combines all three components of inventory.

The records on this company are based on a half-year statistics for each of the years 1990 and 1991.

na $=$ no available data

process orientation is moderate, but not significant, at $r=0.43$, lending some support for Proposition $2 \mathrm{~b}$.

Qualitative observations. It is interesting to compare how the level of CI communications changed over time in Sunshine and Nuts and Bolts. Sunshine is a process-oriented company and Nuts and Bolts is a results-oriented company (Table 1). Sunshine's CI communications gained momentum over time, whereas Nuts and Bolts' CI communications lost momentum over time. By the latter half of 1991, Nuts and Bolts had dissolved its CI committee for lack of communication; Sunshine had increased the level of $\mathrm{CI}$ communications by expanding its $\mathrm{CI}$ program into a company-wide effort.

At the time of the survey, Heat showed the lowest level of CI communications and Progressive showed the highest level (Table 7). In Progressive, every department was asked to work toward CI and to submit a list of improvements at the end of 
Table 7: General CI communications, process orientation and CI effectiveness.*

\begin{tabular}{lcccc}
\hline Companies & $\begin{array}{c}\text { Percent of CI } \\
\text { Communications }\end{array}$ & $\begin{array}{c}\text { Percent Process- } \\
\text { Oriented }\end{array}$ & $\begin{array}{c}\text { Mean Respondent } \\
\text { Perceived CI }\end{array}$ & $\begin{array}{c}\text { Mean Observer } \\
\text { Rated CI } \\
\text { Effectiveness }\end{array}$ \\
\hline Progressive & 58 & 83 & 4.0 & 4.2 \\
Sunshine & 45 & 65 & 2.9 & 3.4 \\
Heat & 21 & 37 & 2.1 & 2.0 \\
Topheavy & 41 & 33 & 2.8 & 2.3 \\
Mom and Pop & 49 & 14 & 2.6 & 1.2 \\
Small & 42 & 10 & 2.3 & 1.1 \\
Nuts and Bolts & 34 & 8 & 2.8 & 3.0 \\
\hline
\end{tabular}

*Refers to percent of CI communications occurring "occasionally" or "often."

$r=0.43$ between process orientation and $\mathrm{CI}$ communication.

$r=0.77$ between $\mathrm{CI}$ communication and perceived $\mathrm{CI}$ impact.

$r=0.34$ between $\mathrm{CI}$ communication and rated $\mathrm{Cl}$ effectiveness.

each month, which was promptly posted for the other departments to review. In 1991, the average number of $\mathrm{CI}$ changes per department per month ranged from five to ten. They had altogether more than 400 recorded CI changes in that year. On the contrary, Heat appeared to have serious communication problems. There was virtually no sharing of the company performance data with employees. The CI committee had been trying to post some data, but it had been approved in a limited way. The management was reluctant at first even to allow the CI committee to post the employee suggestion rates.

\section{The Intervening Role of CI Communications Directed to Workers (Proposition 3a and 3b)}

Quantitative results. Table 8 shows the values for mean worker "centrality," which is computed from the symmetric communication matrix. These values are an indicator of the CI communications to and from workers. Table 9 focuses on the CI communications directed to workers. This is called "indegree centrality," whose values are computed from the asymmetric communication matrix.

Reviewing Table 8, all correlations are substantial to high, supporting Propositions $3 \mathrm{a}$ and $3 \mathrm{~b}$. However, Table 9 isolates the important aspect of communication involving workers. It shows that the correlations with $\mathrm{CI}$ communications directed to workers are higher. This means the explained variance of $\mathrm{CI}$ communications involving workers that we observed in Table 8 came mostly from the communications going to the workers, rather than communications coming from the workers. All correlations associated with CI communications directed to workers are high-with $\mathrm{CI}$ effectiveness, and with percent process orientation. Thus, in support of Propositions $3 \mathrm{a}$ and $3 \mathrm{~b}$, process-oriented companies tend to communicate more to workers about $\mathrm{Cl}$, and this $\mathrm{Cl}$ communication to workers is correlated with $\mathrm{CI}$ effectiveness.

Qualitative observations. The two process-oriented companies (Table 1), Progressive and Sunshine, show the highest worker communications (both non-directional 
Table 8: Worker centrality in CI communication, process orientation and $\mathrm{CI}$ effectiveness.

\begin{tabular}{lcccc}
\hline Companies & $\begin{array}{c}\text { Mean } \\
\text { Worker } \\
\text { Centrality }(\%)\end{array}$ & $\begin{array}{c}\text { Percent } \\
\text { Process } \\
\text { Oriented }\end{array}$ & $\begin{array}{c}\text { Mean Respondent } \\
\text { Perceived CI } \\
\text { Impact }\end{array}$ & $\begin{array}{c}\text { Mean Observer } \\
\text { Rated CI } \\
\text { Effectiveness }\end{array}$ \\
\hline Progressive & 210 & 83 & 4.0 & 4.2 \\
Sunshine & 179 & 65 & 2.9 & 3.4 \\
Heat & 98 & 37 & 2.1 & 2.0 \\
Topheavy & 134 & 33 & 2.8 & 2.3 \\
Mom and Pop & 165 & 14 & 2.6 & 1.2 \\
Small & 112 & 10 & 2.3 & 1.1 \\
Nuts and Bolts & 110 & 8 & 2.8 & 3.0 \\
\hline
\end{tabular}

$r=0.75$ between worker centrality and process orientation.

$r=0.83$ between worker centrality and perceived $\mathrm{CI}$ impact.

$r=0.59$ between worker centrality and rated CI impact.

Table 9: Indegree worker centrality in CI communication, process orientation and CI effectiveness.

\begin{tabular}{lcccc}
\hline Companies & $\begin{array}{c}\text { Mean Indegree } \\
\text { Worker } \\
\text { Centrality (\%) }\end{array}$ & $\begin{array}{c}\text { Percent } \\
\text { Process } \\
\text { Oriented }\end{array}$ & $\begin{array}{c}\text { Mean Respondent } \\
\text { Perceived CI } \\
\text { Impact }\end{array}$ & $\begin{array}{c}\text { Mean Observer } \\
\text { Rated CI } \\
\text { Effectiveness }\end{array}$ \\
\hline Progressive & 162 & 83 & 4.0 & 4.2 \\
Sunshine & 154 & 65 & 2.9 & 3.4 \\
Heat & 56 & 37 & 2.1 & 2.0 \\
Topheavy & 98 & 33 & 2.8 & 2.3 \\
Mom and Pop & 76 & 14 & 2.6 & 1.2 \\
Small & 45 & 10 & 2.3 & 1.1 \\
Nuts and Bolts & 86 & 8 & 2.8 & 3.0 \\
\hline
\end{tabular}

$r=0.86$ between indegree worker centrality and process orientation.

$r=0.86$ between indegree worker centrality and perceived $\mathrm{CI}$ impact.

$r=0.88$ between indegree worker centrality and rated $\mathrm{CI}$ impact.

and directional as shown in Tables 8 and 9), and CI effectiveness (both perceived and rated effectiveness). Both companies had active worker committees at the center of their CI programs. For example, Progressive had the housekeeping and workplace organization committee that reviewed all departments every month and evaluated them. Sunshine had the plant layout committee that met every day and worked on improving the production flow.

One of the three results-oriented companies, Small, shows the lowest level of CI communications directed to workers. As an example, when management had workers perform improvement projects (e.g., color coding of the dies), the workers did not understand the logic behind it. When asked if they knew why they were color-coding the dies, workers' response was that they were merely doing what they 
were told to do. The enthusiasm for work seemed very low among the workers, which was evidenced by high worker turnover. It appeared that management spent little time communicating with workers but merely issued orders. On all CI effectiveness measures, this company shows up consistently as the least effective company.

Mom and Pop is another results-oriented company, but in Table 8, which shows non-directional CI communication, its CI communications involving workers appear quite high. Indeed, the workers at this company did communicate actively about improvement projects; however, as mentioned earlier, the management did not reciprocate the CI-related communication initiated by the workers. The results shown in Table 9 reflect this observation. The score of CI communications directed to workers is one of the lowest. This low score suggests that most of the CI communications surrounding workers were initiated by the workers, but not reciprocated by others in the company.

\section{DISCUSSION}

Meredith posited that "the markets of every country have become global markets with global competitors-Asian, European, American-competing fiercely" [37, p. 2]. How well a business delivers quality products at low cost in a responsive manner will determine "whether it remains in business, goes bankrupt, or sells out to better managed competitors" [37, p. 2]. To rise up to the international challenge, many firms have focused on making improvements through major, discontinuous changes such as organizational restructuring and reengineering. Borucki and Barnett pointed out how "the new rules of doing business in global economy have forced . . . a deep structural crisis" in firms [5, p. 36], leading to major reshuffling of organizational structure and work processes. Roach [50, p. 82] also argued for "the restructuring imperative" in the face of foreign competition. In general, the literature reports of dramatic and framebreaking changes arising from the globalization of businesses [39] [40].

In this study, we focused on the other aspect of making improvements-continuous incremental improvement. We treat $\mathrm{CI}$ as a set of tools and a philosophy that promotes small, incremental, but continuing change, which has a critical implication for global competition per Poirier and House's statement that "business has become a global matter, and the competitors who are winning are doing so because they have made (continuous) improvement their defining character" [45, p. 11]. We believe CI offers an alternative to making radical changes such as organization restructuring in this global economy. Dertouzos, et al. [13] posited that American companies began to make $\mathrm{CI}$ changes when they realized their overseas competitors were making improvements in the quality and reliability of products and services at a faster rate. Fearing being driven "out of the marketplace," many firms saw the need to overcome "the status quo" and began to implement CI changes [20, p. 35]. In this paper, we focused on organizational processes and management approaches compatible with this new approach to organizing. We identified a number of factors that are positively related to effective implementation of the CI paradigm.

First, our data suggested that process orientation, compared to results orientation, is more integral in CI effectiveness. This observation could not be anticipated from the social science literature on values, but there have been so many strong assertions 
in the management literature on quality methods that this is true. To our knowledge, we were the first to examine these assertions through empirical studies. However, we caution that our study was largely exploratory, limited in the number of plants, thus, lacking generalizability of the results. Nonetheless, the role of value orientation on CI effectiveness raises some interesting international questions. On the one hand, we found clear evidence of differences across plants in the degree to which key implementers held process orientations, and this was associated with successful CI implementation. This is consistent with Brannen's [6] argument that the "culture of work" may matter more than national culture in the degree to which Japanese manufacturing methods can be successfully applied in the U.S. On the other hand, we did not have comparative Japanese data. It is possible that a much larger proportion of Japanese plants would include a large proportion of process-oriented managers, and this is due to a national cultural influence as Imai [31] seemed to indicate.

Second, we found that informal communication networks are strongly related to effectively implementing CI. This finding is consistent with a good deal of literature that finds communication networks are important to a variety of technological and organizational changes. Certainly, CI, which depends on the voluntary and continuing contributions of everyone in the organization to make many small changes, should be dependent on effective communications. Informal communication activities at the personal level are key in establishing an active CI program. The communications surrounding workers seemed to play a critical role. In particular, the communications directed to workers are a powerful predictor of $\mathrm{CI}$ effectiveness. The implication of this point is particularly salient in the global context. Corbett and Van Wassenhove [8] and Suzaki [65] suggested that human resources is the last source of competitive advantage in the global market. How a firm harnesses the knowledge and creativeness of workers through informal networks will become a critical differentiating element.

Third, we discovered that the degree of process orientation was related to the company's propensity for communicating about CI. Members of companies with a higher proportion of process-oriented respondents communicated more often about CI. They also showed a higher tendency to communicate to the workers. In the international context, this lesson may have implications for how managers from different cultures communicate about improvement ideas. That is, the functioning of global alliances may be influenced by value orientations. A number of important research questions arise about global alliances. Is there a relationship between value orientations and the kinds of benchmarking information the company seeks from partners? When do they seek short-term quick fix versus long-term strategic information? Will value orientations cause some partners in a global alliance to focus on immediate results while others focus on processes? Will this cause conflict between different partners possessing different value orientations? To the extent that these value orientations are influenced by national culture, this could have important implications for alliances between specific pairs of countries. For example, to what degree will resultsoriented partners listen to and consider suggestions of alliance partners?

Moreover, the size of the correlations were striking, and a number of them were statistically significant, even with the sample size of seven. It is tempting from these strong patterns of association to draw causal inferences and to prescribe specific actions and ways of thinking for managers. Of course, what we really demonstrated 
is that in a small sample, sets of characteristics cluster together: process-oriented value orientations, use of informal communication networks, and measures of the effectiveness of $\mathrm{CI}$. We can neither prove causality with this research design, nor can we sort out which variables were more important than others, which were exogenous, and which had mediating relationships. However, the small sample size and use of multiple data collection methods allowed us to collect data at a level of depth that would have been prohibitively expensive with a large sample study.

If, in fact, process-oriented values are necessary to effectively implement $\mathbf{C I}$, then what is to be done? Should managers attempt to change their basic values, or perhaps hire individuals who have process-oriented values in a position of authority? Should managers abandon a focus on results and simply do what seems like the right thing to do without regard for consequences? Because private enterprises exist to make money, we certainly do not advocate abandoning a focus on results, and there is little danger of this happening. In fact, we observed previously that managers in this study tended to be results-oriented. We also do not believe that process orientation and results orientation are mutually exclusive. Rather, we believe it is a matter of degree. Our society is certainly results-oriented. For example, note the slogan, "Winning isn't everything, it is the only thing." And reward systems in business do seem to promote a results orientation. So, no extraordinary methods seem necessary to further ensure that managers focus on results. But we do suspect that process orientation comes less naturally to U.S. managers. Thus, as a compensatory mechanism, it may be necessary for managers to emphasize process-oriented values in order to redress the balance.

There are many open questions remaining about the role of process versus results orientations in managing quality through $\mathrm{CI}$. Are these values really causally related to successful $\mathrm{CI}$ programs? To what degree are they mutually exclusive, and to what degree can these value orientations coexist in the same individual? Are managerial values more important in smaller firms where there is a more intimate connection between managers and workers, compared to relationships at large firms? Is a results orientation more important for more radical organizational transformations? That is, what kinds of tasks and environments are better suited for process-oriented versus results-oriented individuals? Our research suggests that more scholarly attention should be focused on the interplay of values and communication networks in studies of quality management through $\mathbf{C I}$.

\section{IMPLICATIONS FOR FUTURE RESEARCH}

We have already discussed some implications of the process versus results value distinction for global quality management research. A number of unanswered questions were raised. We consider two additional issues here that are pragmatically oriented. First, we consider whether value orientations are permanently ingrained, or can be changed. Second, we consider the implications for a process orientation on measures of organizational effectiveness.

\section{Training Versus Selection}

As process-oriented values seem to lead to more effective CI activities, what are the implications for human resource management? Two possibilities are apparent. 
One is that because personal value systems reside deep within each individual's psyche, they are stable and tend to be invariant. In this case, the training of such value orientations may be difficult, and the company may do better to screen for process-oriented employees at initial hiring. However, this paints a dire picture for those who are results-oriented, in that it is not clear whether we can accurately assess this value orientation, and this type of screening seems unethical. Therefore, a second possibility is considered. There are scholars who argue that a personal value system is a dynamic entity that can be influenced and changed. For example, Parsons and Shils [43] suggested that new values can be learned and shaped. They argued that values can change through subjective experience rather than through deductive reasoning. If this is so, it implies that in-class training, which typically teaches through deductive reasoning, may not be effective in changing personal value systems, but exposure to subjective experience through participation in improvement projects may be an effective medium for instilling new values. There has been evidence for this implication in the case examples. At Progressive, a few of the older workers who resisted making incremental changes to improve the work organization (i.e., they saw no value in organizing their work stations) started to "come around" by the end of 1991 .

The answer to whether the personal value system is dynamic can be addressed by running a second wave of the survey by the same seven companies and probing for changes in the individual respondent's value orientations. If there is change, it implies that value systems are indeed dynamic. The task then becomes discovering ways to alter the results orientation to more of a process orientation. This can perhaps be learned by noting the direction of value orientation changes, studying activities on which each company has focused (i.e., exposure to what type of subjective experience), and correlating the type of experience with the direction of value orientation changes. There may be four possible directions of change: process becoming more process, results becoming more results, process becoming more results, and results becoming more process. For example, whether or not an individual was a member of a CI committee constitutes varying experience. Whether or not an individual was one of the leading figures of $\mathrm{CI}$, and/or whether he/she had to deal with management who demanded short-term cost analysis for every change, may also constitute different experiences and may show different directions of value change. Finally, once the types of value change and types of actual experiences are sorted and correlated, one may be able to make a statement about the particular types of experience necessary to change the values to more process orientation.

\section{Organizational Effectiveness}

Obviously, business organizations care about results and the philosophy of CI emphasizes the value of systematic measurement of progress versus goals. But, if a results orientation can be harmful to implementation of $\mathrm{CI}$, what should an organization measure? We are not arguing that organizations should abandon a results orientation and stop measuring data like final product quality, customer returns, sales, and unit cost. But a process-oriented definition of effectiveness also suggests one should consider what occurs within the process of organizing and managing the enterprise. One possible approach is to define effectiveness at the internal vendor-customer 
interfaces where everyone in the organization is considered both a vendor and a customer. These internal effectiveness scores can then be summed up for one system's level effectiveness score. How detailed the internal process needs to be broken up, or how they can be summed up, is suggested as an agenda for future research.

The past definition of organizational effectiveness focused on the result of the "throughput." This results-oriented effectiveness is typically defined in terms of the system's goal and the characteristics of the output [63]. We propose complementing these outcome-oriented measures with measures of the internal process. In other words, a focus on throughput "process" should accompany a focus on throughput "product." When effectiveness was defined based on the final product, the process was often considered a black box. When management realized they had not met the target and thus had low effectiveness, it was often difficult to find out what went wrong within the process. With the process-oriented way of defining effectiveness, the process would be less opaque and more readily analyzable. Statistical process control is one example of a process measure. When companies look at the process in this way, problems can be anticipated rather than detected after the fact.

This new process-oriented definition of effectiveness complements the more traditional "internal process approach" to effectiveness that scholars adopt to study the relationship between human resources and their effectiveness in organizations [1] [35]. According to Daft [10], these scholars have tended to focus on the effectiveness indicators based on general human resource issues; for example, management's concern for workers' well being, teamwork, and trust.

What a process orientation of CI brings to this research is customer orientation and logical reduction of the work process with the notion of the "mini-company" [65]. The internal work process is broken up into mini-companies at the internal customer-vendor interface. The satisfaction of internal customers is how the processoriented effectiveness starts to get computed and eventually accumulated for the systems' level effectiveness score. Furthermore, this internal customer satisfaction should be dependent on ultimate external customer satisfaction so that organizational effectiveness finds a common evaluative frame.

In summary, the process-results value distinction plays an important role in the implementation of $\mathrm{CI}$, which many theorists have argued is critical to business competitiveness. Moreover, we have suggested that this value orientation has important researchable implications for global quality management, human resource management, and the very conception of organizational effectiveness. [Received: July 7, 1994. Accepted: August 29, 1995.]

\section{REFERENCES}

[1] Argyris, C. Integrating the individual and the organization. New York: Wiley, 1964.

[2] Baron, R. M., \& Kenny, D. A. The moderator-mediator variable distinction in social psychological research: Conceptual, strategic, and statistical considerations. Journal of Personality and Social Psychology, 1986, 51(6), 1173-1182.

[3] Bernard, H. R. Research method in cultural anthropology. Newberry Park, CA: Sage, 1988. 
[4] Borgatti, S., Everett, \& Freeman, L. UCINET Version 1.0. Columbia, SC: Analytic Technologies, 1992.

[5] Borucki, C., \& Barnett, C. K. Restructuring for self-renewal: Navistar International Corporation. Academy of Management Executive, 1990, 4(1), 36-49.

[6] Brannen, M. Y. Does culture matter? Negotiating a complementary culture to successfully support technological innovation. In J. K. Liker, J. E. Ettlie, \& J. C. Campbell (Eds.), Engineered in Japan: Japanese technology management practices. New York: Oxford University Press, 1995.

[7] Choi, T. Y., \& Wasti, S. N. Institutional pressure and organizational learning: The case of American-owned automotive parts suppliers and Japanese shop floor production methods. In J. K. Liker, J. E. Ettlie \& J. C. Campbell (Eds.), Engineered in Japan: Organization and technology. New York: Oxford University Press, 1995.

[8] Corbett, C. J., \& Van Wassenhove, L. K. The green fee: Internalizing and operationalizing environmental issues. California Management Review, 1993, 36, 116-135.

[9] Crano, W. D. Triangulation and cross-cultural research. In M. B. Brewer \& B. E. Collins (Eds.), Scientific inquiry and the social sciences. San Francisco: Jossey-Bass, 1981.

[10] Daft, R. L. Organization theory and design. New York: West Publishing Company, 1989.

[11] Deming, W. E. Out of the crisis. Cambridge, MA: MIT Press, 1986.

[12] Denison, D. Corporate culture and organizational effectiveness. New York: Wiley, 1990.

[13] Dertouzos, M. L., Lester, R. K., \& Solow, R. M. Made in America: Regaining the productive edge. Cambridge, MA: MIT Press, 1989.

[14] Director. Kaizen: Changing for the better, 1993, 46(12), 15-16.

[15] Downey, H. K., \& Ireland, R. D. Quantitative versus qualitative: The case of environmental assessment in organizational studies. In J. Van Maanen (Ed.), Qualitative methodology. Newbury Park, CA: Sage, 1983.

[16] Eisenhardt, K. M. Building theories from case study research. Academy of Management Review, 1989, 14(4), 532-550.

[17] Etienne-Hamilton, E.C. Operations strategies for competitive advantage. New York: Dryden Press, 1994.

[18] Etzioni, A. The moral dimension: Toward a new economics. Cambridge, MA: Ballinger, 1988.

[19] Fielding, N. G., \& Fielding, J. L. Linking data. Newbury Park, CA: Sage, 1986.

[20] Fleming, R., \& Rother, M. A practical approach to continuous improvement. Metal Forming, 1991, August: 35-38.

[21] Freeman, L. C. Centrality in social networks: Conceptual clarification. Social Networks I, 1979, 215-239.

[22] Gabor, A. The man who discovered quality. New York: Times Books, 1990.

[23] Garvin, D. A. Managing quality: The strategic and competitive edge. New York: The Free Press, 1988. 
[24] Guilford, J.P. Fundamental statistics in psychology and education. New York: McGraw-Hill, 1965.

[25] Hage, J., \& Dewar, R. Elite values versus organizational structure in predicting innovation. Administrative Science Quarterly, 1973, 18(3), 279-290.

[26] Heyne, P. The economic way of thinking. Chicago: Science Research Associates, 1976.

[27] Hirsch, P. M., Friedman, R., \& Koza, M. P. Collaboration or paradigm shift? Caveat emptor and the risk of romance with economic models for strategy and policy. Organization Science, 1990, 1(1), 87-97.

[28] Hofstede, G., Neuijen, B., Ohayv, D.D., \& Sanders, G. Measuring organizational cultures: A qualitative and quantitative study across twenty cases. Administrative Science Quarterly, 1990, 35, 286-316.

[29] Imai, M. Kaizen: The key to Japan's competitive success. New York: Random House, 1986.

[30] Ishikawa, K. What is total quality control?: The Japanese way. Englewood Cliffs, NJ: Prentice-Hall, 1985.

[31] Japan Management Association. The source of profit is in the manufacturing process. In A. Robinson (Ed.), Continuous improvement in operations: A systematic approach to waste reduction. Cambridge, MA: Productivity Press, 1988.

[32] Jick, T. D. Mixing qualitative and quantitative methods: Triangulation in action. In J. Van Maanen (Ed.), Qualitative methodology. Newbury Park, CA: Sage, 1983.

[33] Juran, J. M. Juran on planning for quality. New York: Free Press, 1988.

[34] Kluckhohn, C. Values and value orientations in the theory of action: An exploration in definition and classification. In T. Parsons \& E. Shils (Eds.), Toward a general theory of action. Cambridge, MA: Harvard University Press, 1954.

[35] Likert, R. The human organization. New York: McGraw-Hill, 1967.

[36] March, J. G., \& Olsen, J. P. Rediscovering institutions: The organizational basis of politics. New York: Free Press, 1989.

[37] Meredith, J. R. The management of operations: A conceptual emphasis. New York: Wiley, 1992.

[38] Meyer, A. Adapting to environmental jolts. Administrative Science Quarterly, 1983, 27, 515-537.

[39] Miller, D., \& Friesen, P. Organizations: A quantum view. Englewood Cliffs, NJ: Prentice Hall, 1984.

[40] Nadler, D. A., \& Tushman, M. Organizational frame bending: Principles for managing reorientation. Academy of Management Executives, 1989, 1, 194-204.

[41] Nakajima, S. TPM development program: Implementing total productive maintenance. Cambridge, MA: Productivity Press, 1989.

[42] Nemoto, M. Total quality control for management. Englewood Cliffs, NJ: Prentice Hall, 1987. 
[43] Parsons, T., \& Shils, E. Systems of value orientation. In T. Parsons \& E. Shils (Eds.), Towand a general theory of action. Cambridge, MA: Harvard University Press, 1954.

[44] Poe, R. The new discipline: Unleash group intelligence in your company. Success, July/August: 80, 1991.

[45] Poirier, C. C., \& Houser, W. F. Business partnering for continuous improvement. San Francisco: Berrett-Koehler, 1993.

[46] Rice, R. E., \& Aydin, C. Attitudes towards new organizational technology: Network proximity as a mechanism for social information processing. Administrative Science Quarterly, 1991, 36, 219-244.

[47] Rice, R. E., Grant, A. E., Schmitz, J., \& Torobin, J. Individual and network influences on the adoption and perceived outcomes of electronic messaging. Social Networks, 1990, 12, 27-55.

[48] Rice, R. E., \& Richards, W. D. An overview of network analysis methods and programs. In B. Dervin \& M. J. Voigt (Eds.), Progress in communication sciences (Vol. 6). Norwood, NJ: Ablex, 1985.

[49] Richards, W. D. FATCAT. Vancouver, Canada: Department of Communication, Simon Fraser University, 1991.

[50] Roach, S. S. Services under siege-The restructuring imperative. Harvard Business Review, 1991, 69(5), 82-91.

[51] Robinson, A. Origins of the modern Japanese management style: Kaizen and elimination of waste. In A. Robinson (Ed.), Continuous improvement in operations: A systematic approach to waste reduction. Cambridge, MA: Productivity Press, 1991.

[52] Rogers, E. M. Diffusion of innovations. New York: Free Press, 1983.

[53] Rogers, E. M., \& Kincaid, D. L. Communication networks: Toward a new paradigm for research. New York: Free Press, 1981.

[54] Rokeach, M. Beliefs, attitudes, and values. San Francisco: Jossey-Bass, 1970.

[55] Rokeach, M. The nature of human values. New York: The Free Press, 1973.

[56] Ross, J. E. Total quality management: Text, cases and readings. Delray Beach, FL: St. Lucie Press, 1993.

[57] Schaffer, R. H., \& Thompson, H. A. Successful change programs begin with results. Harvard Business Review, 1992, 70(1), 80-89.

[58] Schonberger, R. J. Japanese manufacturing techniques. New York: The Free Press, 1982.

[59] Schroeder, D. M., \& Robinson, A. G. America's most successful export to Japan: Continuous improvement programs. Sloan Management Review, 1991, Spring, 67-81.

[60] Scott, J. Social network analysis. Newbury Park, CA: Sage, 1991.

[61] Shingo, S. Non-stock production: The Shingo system for continuous improvement. Cambridge, MA: Productivity Press, 1988.

[62] Stevens, T. Continuous improvement in maintenance. Maintenance Technology, 1990, April, 31-34. 
[63] Strasser, S., Eveland, J. D., Cummins, G., Deniston, O. L., \& Romani, J. H. Conceptualizing goal and systems models of organizational effectiveness: Implications for comparative evaluation research. Journal of Management Studies, 1981, 18, 321-340.

[64] Suzaki, K. The new manufacturing challenge: Techniques for continuous improvement. New York: The Free Press, 1987.

[65] Suzaki, K. The new shop floor management: Empowering people for continuous impmovement. New York: The Free Press, 1993.

[66] Tichy, N. M. A social network perspective for organization development. In T.G. Cummings (Ed.), Systems theory for organization development. New York: Wiley, 1980.

[67] Tichy, N. M. Networks in organizations. Handbook of Organization Design, 2, 1981.

[68] Tichy, N. M. Managing strategic change: Technical, political, and cultural dynamics. New York: Wiley, 1983.

[69] Townsend, P. L. Commit to quality. New York: Wiley, 1986.

[70] Wellman, B. Network analysis: Some basic principles. In R. Collins (Ed.), Sociological theory. San Francisco: Jossey-Bass, 1983.

[71] Womack, J. P., Jones, D. T., \& Roos, D. The machine that changed the world. New York: Rawson Associates, 1990.

[72] Yin, R. K. Case study research: Design and methods. Newbury Park, CA: Sage, 1989. 


\section{APPENDIX A: QUESTIONNAIRE}

\section{Value Question}

How would each of those listed below (including yourself) respond in each of the following situations? For each person, check either A or B for all three situations.

Situation 1. When doing a job,

$\square$ A. Get it done right at ALL costs.
B. Get it done as efficiently as possible in MINIMUM time.

Situation 2. I just worked on a product and found out that it has what I would consider a minor quality problem. I suspect that this problem will not affect product functioning.

$\square$ A. Call the customer and ask for an extension so that I can fix the problem.
B. Send it out since I feel meeting the deadline is important.

\section{Situation 3. Someone suggests my company invest in a new program.}

a. Vote for investing if it sounds like the right thing to do. $\square \mathrm{B}$. Vote for investing only if the payback schedule is reasonable.

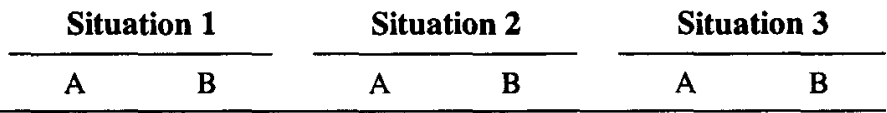

(Names here below)*

*The number of rows would equal the number of total respondents in each company.

\section{Communication Question}

Your company joined the Continuous Improvement Users Group (CIUG) last October. Since then, your company has been involved in making various types of continuous improvement ( $\mathrm{CI}$ ) changes. Make one check mark for each person. How frequently has each of the following persons talked to you about $\mathrm{CI}$ ?

\begin{tabular}{lllll}
\hline & Never & Rarely & Occasionally & Often \\
\hline (Names here below) & & & & \\
\hline
\end{tabular}

\section{APPENDIX B: COMPANY DESCRIPTIONS}

\section{Progressive Engineering and Manufacturing}

Members of Progressive were the first who took advantage of what they learned from the CIUG. In December 1990, they began to work on housekeeping and workplace organization (HKWO), after taking a videotape of their workplace and showing it to all employees. "Everyone realized that their work organization needed 
improvement." As a result, the company shut down and underwent a major cleanup. Interestingly, after this one month, their quality level took a quantum leap from about 20 incidents of recorded quality problems per month to only about 4 and was maintained throughout the year 1991. The company proceeded to set up various self-managing worker committees and systematically attacked housekeeping and workplace organization, reduction of set-up time, machine maintenance. The housekeeping and workplace organization committee, in particular, had its own budget. This committee evaluated all departments on a monthly basis and gave an award to the best department each month.

\section{Sunshine Incorporated}

Management shared financial and operational information with workers, and thus, mutual trust between management and workers was high. The CI program at Sunshine, however, started out slowly. At first, the managers focused on engineering and administrative changes that were indirectly related to the concept of $\mathrm{CI}$. One of the three CIUG consultants lamented at the time that managers at Sunshine did not seem to "quite grasp the concept of CI yet." Changes began to take place during the summer of 1991, when workers who were not assigned to the committee set up "problem boards," and on their own initiative, began to work on shopfloor problems. Soon after that, managers posted a sign-up sheet for the workers to join the crossdepartmental "CI committees." This seems to have marked the turning point. The committees were "let loose" to improve their own respective areas. By early 1992, the CI program was beginning to develop strong roots in the company.

\section{Heat Incorporated}

This company represents a story of one person's struggle against an apathetic organizational infrastructure. The overall sentiment of the company's members was that "we are doing well, and why should we bother to change." Against the apathetic climate, the $\mathrm{CI}$ leader used his personal influence to recruit people from various parts of the company, and organized an internal $\mathrm{CI}$ committee. The $\mathrm{CI}$ committee remained very active, designing changes and trying to implement them. Nonetheless, many proposed changes were not approved by management, and even when approved, they were met with heavy resistance from other middle managers. One example happened in the late fall of 1991. The CI committee developed a standard operating procedure for assembling one of the machines, which had been shown to save time in training and trouble shooting. The top management was enthusiastic about the results. However, this standard operating procedure was met with severe resistance from other departments. Early in the next year, 1992, the resistance won out and the newly developed procedure was abandoned.

\section{Topheavy Tool and Manufacturing Company}

This company had no active employee-involvement programs during the time of this research. One characteristic of Topheavy that worked against it was a status gap between managers and line workers. Managers appeared very possessive of financial information, and they were rather reluctant to share it with workers. At Topheavy, 
CI remained a management project; it never really made it to the worker level, because the two CI committees did not include line workers. Early in 1991, the operations manager explained that the reasons for not including workers in their $\mathbf{C I}$ committees was a deliberate strategy to "get the buy-in of managers first and then worry about the workers." However, he was later asked to resign in May, and, in fact, the reason for his resignation was explained as his inability to "build a team" of managers and workers. It was ironic then that the second CI committee also did not include any workers, and it "never kept up the suggestions" they decided to implement during the kick-off meeting. The manager who was appointed to lead this second CI committee also left the company soon after the committee was dissolved later in the year. A few changes made in the name of $\mathrm{CI}$ in this company were done by one staff person who attended the CIUG meetings most regularly.

\section{Mom and Pop Manufacturing}

Mom and Pop had two sources of employee participation. One, quality work groups (QWG), was a result of training in the Crosby System, and the other was the internal CI group led by three CIUG participants. Despite the existence of two avenues of participation, the total number of actual changes were dismally low. The three CIUG participants tried to "sell the idea of CI." They were, however, very discouraged throughout the entire year of 1991 because the CI group proposed a number of changes, but was not allowed to implement them. The QWGs were ineffective mainly due to the communication gap between them and the quality improvement team (QIT), a management team. The QWGs would submit a proposal for a new project to the QIT, but "would not hear from them for months." Toward the end of 1991, the company was undergoing a downsizing effort, and as people left, there appeared to be gaps in leadership for the QWGs. In December of 1991, with a smaller number of workers, management reduced the number of QWGs to three and appointed the three CIUG participants to lead the QWGs.

\section{Small Stamping and Manufacturing Company}

This company joined the CIUG to stop their "saw-tooth improvement" and to "share ideas" with other companies. They were "tired of" making improvements only to see their efforts decay. However, "saw-tooth improvement" is what they did in their $\mathrm{CI}$ efforts, and "stop sharing" is what they did when they became the only company whose members stopped coming to the CIUG meetings toward the end of 1991. They made cosmetic changes; they did not incorporate the changes into either the work process or standard operating procedures. They were more preoccupied with immediate production problems, that is, with "putting the fires out." High turnover of workers aggravated the situation. Most of the workers who were involved in the initial CI projects had left the company by the end of the research.

\section{Nuts and Bolts Machine Company}

The management of this company was first attracted to $\mathrm{CI}$ because it realized the importance of making incremental changes. According to one top manager, "We learned from $\mathrm{CI}$ that making a lot of (connecting) base hits is a lot better than making 
a few (unconnecting) home runs." However, as it turned out, the company stopped making base hits about half way through the year and went for a home run in the end by completely reorganizing its organizational infrastructure. Nuts and Bolts set up a CI committee in January of 1991, which implemented many incremental changes during the next few months. Committee members met twice a week and worked quite feverishly to make changes. However, they seemed to gather little support from the other workers, and the committee members, in turn, tended to talk down to workers who did not understand the importance of making changes. In the fall of 1991, top managers contended that the CI group, though effective in making a number of changes, had worked as "an island" in the company. Management implied that there had not been much integration between the CI members and other workers. Management dissolved the CI committee, and, instead, planned to completely overhaul the organizational infrastructure.

Thomas Y. Choi is assistant professor of management at Bowling Green State University. He received a Ph.D. in industrial and operations engineering from the University of Michigan. He has published articles in the Journal of Engineering and Technology Management and OMEGA: The International Journal of Management Science. His research has focused on quality management, supplier chain management, and organization change.

Jeffrey K. Liker is associate professor of industrial and operations engineering at the University of Michigan and director of the Japan Technology Management Program. He is lead author of an edited volume of research entitled Engineered in Japan: Japanese Technology Management, and has published articles in the Harvard Business Review and Sloan Management Review. 